\title{
Ortaokul Öğrencileri İçin Fene Yönelik Epistemolojik İnanç Ölçeği Geliştirilmesi: Geçerlik ve Güvenirlik Çalışması ${ }^{1}$
}

\author{
Oktay KIZKAPAN ${ }^{2}$ ve Oktay BEKTAŞ ${ }^{3}$
}

\section{$\ddot{\mathrm{O} z}$}

Bu çalşşada doğrudan ortaokul seviyesindeki öğrencilerin epistemolojik inançlarını ölçmeye yönelik bir ölçek geliştirmek amaçlanmıştır. Bu amaç doğrultusunda öncelikle 64 maddeden oluşan bir madde havuzu oluşturulmuştur. Testin kapsam geçerliği için hazırlanan bu ön uygulama formu ölçek geliştirme ve epistemolojik inançlarla ilgili çalışmaları bulunan iki fen eğitim uzmanı tarafindan incelenmiştir. Bu maddeler Kayseri ili Kocasinan İlçesindeki yedinci ve sekizinci sınıfta okuyan 700 yedinci ve sekizinci sınıf öğrencisine uygulanmıştır. Elde edilen veriler üzerinden açımlayıcı ve doğrulayıcı faktör analizi ve güvenirlik analizleri gerçekleştirilmiştir. Faktör analizleri sonucunda ölçeğin dört boyutlu bir yapıda olduğu bulunmuş ve doğrulanmıştır. Bu boyutlar kesin bilgi, bilginin kaynağı, öğrenme yeteneği doğuştandır ve bilginin gelişimi olarak isimlendirilmiştir. Ölçeğin Cronbach Alfa güvenirlik katsayısı "kesin bilgi" alt boyutu için .846, "bilginin kaynağı" alt boyutu için .812, "öğrenme yeteneği doğuştandır" alt boyutu için .610 ve bilginin gelişimi alt boyutu için .616 olarak bulunmuştur. Dolayısıyla ölçeğin güvenilir olduğu kabul edilmiştir. Nihai olarak ortaokul öğrencilerin fene yönelik epistemolojik inançlarını ölçmeyi amaçlayan ölçeğin geçerli ve güvenilir olduğu ve ortaokul düzeyindeki öğrencilerin epistemolojik inançlarını belirlemek amacıyla kullanılabileceği anlaşılmıştır.

Anabtar Kelimeler: Epistemolojik İnanç Ölçeği, Ölçek geliştirme, Ölçme ve değerlendirme, Geçerlik, Güvenirlik

\section{Developing a Science-Oriented Epistemological Belief Scale for Secondary School Students: A Validity and Reliability Study}

\begin{abstract}
The aim of this study is to develop a scale that directly measures the epistemological beliefs of elementary school students. For this purpose, a pool consisting of 64 items was created. The pre-application form was examined by two science education experts who had studies on scale development and epistemological beliefs for the content validity. These items were applied to 700 seventh and eighth grade students in Kocasinan district of Kayseri. Exploratory and confirmatory factor analysis and reliability analyzes were performed on the obtained data. As a result of the factor analysis, it was found that the scale has a four-dimensional structure and it was confirmed. These dimensions are named as certain knowledge, source of knowledge, innate ability and development of knowledge. Cronbach Alpha reliability coefficient of the scale was found to be .846 for the "certain knowledge" sub-dimension, .812 for the "source of knowledge" sub-dimension, .610 for the "innate ability" sub-dimension, and .616 for the "development of the knowledge" sub-dimension. Finally, it was understood that the scale, which aims to measure the epistemological beliefs of secondary school students in science, is valid and reliable and can be used to determine the epistemological beliefs of secondary school students.
\end{abstract}

Key Words: Epistemological Belief Scale, Scale development, Measurement and evaluation, Validity, Reliability

\section{Atıf İçin / Please Cite As:}

Kızkapan, O. ve Bektaş, O. (2020). Ortaokul öğrencileri için fene yönelik epistemolojik inanç ölçeği geliştirilmesi: Geçerlik ve güvenirlik çalışması. Manas Sosyal Araștırmalar Dergisi, 9(4), 2173-2185.

Geliş Tarihi / Received Date: 30.03.2020

Kabul Tarihi / Accepted Date: 02.05.2020

\footnotetext{
${ }^{1}$ Bu çalışma birinci yazarın ikinci yazar danışmanlığında hazırladığı doktora tezi kapsamında geliştirilen veri toplama aracına ilişkin verilerden üretilmiştir.

2 Dr. Öğr. Üyesi- Nevşehir Hacı Bektaş Veli Üniversitesi Eğitim Fakültesi, okizkapan@nevsehir.edu.tr ORCID: 0000-0001-6781-9879

${ }^{3}$ Doç. Dr. - Erciyes Üniversitesi Eğitim Fakültesi, obektas@erciyes.edu.tr

ORCID: 0000-0002-2562-2864
} 


\section{Giriş}

"Epistemik" terimi genel olarak bilgiyle ve onun edinilmesinin koşullarıyla ilgili iken, bir felsefi girişim olarak, epistemoloji insan bilgisinin kökeni, doğası, sınırları, yöntemleri ve gerekçeleriyle ilgilidir. Ancak psikolojik ve eğitimsel bakış açısına göre ise, kişisel epistemoloji konusunda çalışanlar bireylerin bilgi ve bilme kavramlarını nasıl geliştirdikleri ve bunları dünyayı anlamada nasıl kullandıklarına odaklanmaktadır. Dolayısıyla kişisel epistemolojinin kapsamında bilginin ne olduğu (tanımı), nasıl inşa edildiği, nasıl değerlendirildiği, nerede bulunduğu ve nasıl oluştuğu hakkındaki inançlar yer almaktadır (Hofer ve Pintrich, 2012). Kişisel epistemolojik inançlara dair farklı araştırmacılar tarafından farklı tanımlamalar yapılmıştır. Bunlardan Perry (1981) epistemolojik inançları bireyleri bilginin nasıl elde edilebildiğine, ne olduğuna, kesinliğinin derecesine, sınırlanına ve ölçütlerine ilişkin görüşleri şeklinde tanımlarken, Schommer (1990) bireylerin bilginin doğası ve bilginin öğrenilmesine ilişkin inançları şeklinde epistemolojik inançları tanımlamıştır. Hofer ve Pintrich'e (1997) göre ise epistemolojik inançlar, bilginin ne olduğu, nasıl edinildiği, kesinliğinin derecesi, sınırları ve ölçütleri, doğruluğunun kriterleri, öğrenenler tarafindan nasıl öğrenildiği gibi kişisel görüşlere yanıt vermeye çalışan bir alandır.

Geçmişten günümüze epistemolojik inançların öğrencilerin kavramalarını önemli şekilde etkilediği varsayıla gelmiştir (Schommer, 1990). Epistemolojik inançların öneminin fark edilişi William Perry'nin (1970) "Üniversite Yıllarında Zihinsel ve Ahlaki Gelişim Modeli: Bir Şema” adlı çalışmasıyla başlamıştır. Ayrıca Piaget'de bilişsel gelişim teorisini açıklamak için genetik epistemoloji kavramını kullanarak bu alandaki çalışmalara öncü olmuştur (Hofer ve Pintrich, 1997). Perry öğrencilerin epistemolojik gelişim evrelerinden geçtiği fikrini ortaya atmıştır. Öğrencilerin bu gelişimsel sürecin erken dönemlerinde bilgiyi kesin doğru ya da yanlış olarak gördüklerini ve otoritenin doğru cevabı bildiğini düşündüklerini belirtmiştir. Fakat öğrencilerin gelişimin üst basamaklarına ulaştıkça, bilgiye dair çoklu olasılıkların olabileceği ve kişilerin fikirlere karşı kuvvetli fakat değişebilir bir bağlılık içerisinde olmaları gerektiğini düşündüklerini ifade etmiştir. Perry'nin öncülügüünde gerçekleştirilen bu çalışmalar birçok araştırmacıya ilham vermiş, bu konularda farklı modeller oluşturulmasının yolunu açmıştır. Bu modellerden Perry (1981) ve onu takip eden diğer bazı araştırmacıların (Baxter Magolda, 2004; Chandler, Hallett ve Sokol, 2002; King ve Kitchener, 1994, 2004; Kuhn, Cheney ve Weinstock, 2000) savundukları epistemolojik inançların tek boyutlu ilerleyen aşamalar fikrine karşın, birçok araştırmacı da epistemolojik inançları birbirinden bağımsız boyutlardan oluşan bir düşünce sistemi olarak ele almışlardır (Elder, 2002; Hofer ve Pintrich, 1997; Schommer, 1990; White, Elby, Fredriksen ve Schwarz, 1999). Bu alanda çalışmalar yürüten araştırmacılardan Schommer (1990) epistemolojik inançların tek boyutlu olamayacak kadar karmaşık olduklarını ifade etmiş ve epistemolojik inançların en az beş boyutlu bir yapıda olduğu fikrini savunmuştur. $\mathrm{Bu}$ boyutlar1 yap1, kesinlik, bilginin kaynağ1, öğrenmenin kontrolü ve öğrenmenin hız1 olarak isimlendirmiştir. Schommer'ın (1990) ortaya attığ1 ve daha sonra farklı araştırmacılar (Schraw, Bendixen, ve Dunkle, 2002) tarafından teyit edilen epistemolojik inançların birbirinden nispeten bağımsız olan beş boyutu olduğuna ilişkin deneysel deliller olmasına rağmen bu boyutlar farklı araştırmacılar tarafindan eleştirilmektedir. Hofer ve Pintrich'e (1997) göre Schommer'in (1990) ortaya attı̆̆1 boyutlardan öğrenmenin hızı ve doğuştan gelen yetenek boyutları bilgi ve bilmenin doğasından daha çok öğrenmeye ilişkin inançlar olduğu için, bu boyutlar epistemolojik inanç boyutu olarak ele alınmamalıdırlar. Hofer ve Pintrich'e (1997) göre epistemolojik inançların boyutları bilginin kesinliği (certainty of knowledge), basitliği (simplicity of knowledge), bilmenin kaynağ1 (source of knowing) ve bilmenin gerekçelendirilmesidir (justification for knowing). Bir başka araştırmacı Elder (2002) epistemolojik inanç boyutlarına ilişkin Hofer ve Pintrich'e (1997) paralel şekilde bilimin değişen doğası, bilginin yapıs1, bilginin kaynağ1 ve deneylerin rolü şeklinde dörtlü bir yapı ortaya koymuştur. Epistemolojik inançlarla ilgili başka bir model geliştiren White, Elby, Fredriksen ve Schwarz (1999) ise bilginin yapısı, bilme ve öğrenmenin doğası, günlük yaşama uyarlama, gelişen bilgi ve öğrenme yeteneğinin kaynağı isimleri ile beşli bir yap1 ortaya koymuşlardır. Görüldügü gibi epistemolojik inançların boyutlarının sayısı ve isimleri ile ilgili bir fikir birliği bulunmamasına rağmen, çok boyutlu modellerin epistemolojik inançların alana özgü doğasını hesaba kattıkları için tek boyutlu modellerden üstün oldukları kabul edilmektedir (Hofer ve Pintrich, 1997; Pintrich, 2002).

Farklı araştırmacılar tarafından ortaya atılan epistemolojik inanç boyutlarından bilginin kaynağı boyutundaki inançlar "kişilerin bilgilerini oluştururken otorite veya uzman görüşlerini doğru/güvenilir bilgi olarak doğrudan kabul etmeleriyle"; "kendi bilgilerini bireysel mekanizmalarını kullanarak yani bilgiyi sorgulayarak oluşturmaları" arasında değişiklik göstermektedir. Basit bilgi boyutunda inançlar "bilgi ile ilgili inançların birbirinden bağımsız bilgi parçacıklarından oluştuğu" inancı ile, "bilginin tutarlı bir yap1 
içerisinde birbirleriyle alakalı kavram kümelerinden" oluştuğu inancı arasında değişiklik gösterdiğini düşünmüştür. Bilginin kesinliği boyutunun "bilginin değişmeye açık" ya da "değişmeye dirençli olduğu" inancına odaklandığını belirtilmiştir. Öğrenmenin kontrolü boyutunun "öğrenebilmek için doğuştan yetenekli olmak gerektiğı" inancı ile "ögrrenmenin zaman ve çaba gerektiren bir uğraş olduğu" inanc1 arasında değişiklik gösterdiğini ifade edilmiştir. Öğrenmenin hızı boyutunun "öğrenme ya ilk seferde tamamen gerçekleşir ya da hiç gerçekleşmez" ve "zaman içerisinde çaba ve uğraş sonucu gerçekleşebilir" olduğu inanc1 arasında değiştiğini ifade edilmektedir (Schommer, 1990). Gerekçelendirme boyutu bireylerin kanıt kullanımı, yetki ve uzmanlık kullanımı ve uzmanlar hakkındaki değerlendirmeleri olmak üzere iddiaları nasıl değerlendirdiğini içerir. Bireyler gerekçelendirmeyi öğrendikçe, dualist inançlar, gerekçelendirilmelerin çok yönlü fikirlerle yapılabileceği şeklindeki inançlara evrilir (Hofer ve Pintrich, 1997). Dolayısıyla gerekçelendirme boyutunda bireylerin kendilerine sunulan bilgiyi gerekçelendirmeden kabul etmesi naif inancın göstergesi iken, bilgilerin kanıt kullanarak ve uzman görüşlerini değerlendirerek oluşturulması gelişmiş inancın göstergesidir. Günlük yaşama uyarlama boyutunun ise "bilimsel bilgi ve bilimsel düşüneme yöntemi sadece belirli alanlarda uygulanabilir" olduğu inancı ile "bilimsel bilgi ve bilimsel düşünme yöntemi günlük yaşama ve diğer öğrenme ortamlarına uyarlanabilir" inançları arasında değişiklik gösterdiği ifade edilmektedir (White ve ark., 1999).

Alanyazında farklı epistemolojik inanç modelleri olduğu gibi bu modelleri esas alarak geliştirilmiş ölçeklerin bulunduğu ve bazılarının Türkçe'ye çeviri ve uyumunun yapıldığı görülmektedir (Conley, Pintrich, Vekiri ve Harrison, 2004; Evcim, 2010; Özkan, 2008; Üztemur, Dinç ve İnel, 2018, Yıldıran, Demirci, Bektaş ve Geban, 2011). Yakın zamanda epistemolojik inançlarla ilgili yapılan çalışmalarda ise üst öğrenim düzeyindeki öğrencilerin epistemolojik inançlarını farklı boyutlardan ele almıştır (Topçu ve Yllmaz-Tüzün, 2009). Bu çalışmalarda yüksek akademik başarı gösteren öğrencilerin, epistemolojik inançların boyutlarından bilginin basitliği ve kesinliği boyutlarında da daha sofistike epistemolojik inançlar geliştirdikleri görülmüştür (Kardash ve Scholes, 1996; Schommer, Crouse, ve Rhodes, 1992). Benzer şekilde akademik başarısı yüksek öğrenciler epistemolojik inançların öğrenmenin hızı ve öğrenme yeteneği doğuştandır boyutlarında da gelişmiş epistemolojik inançlar gösterdikleri görülmüsstür (Schommer, 1990; Schommer ve Walker, 1997). Aynı şekilde, Schommer (1993) epistemolojik inançların genel akademik başar1 üzerindeki etkisini incelediği çalışmasında öğrenciler öğrenmenin hızlı, bilginin basit ve kesin, öğrenme yeteneğinin de doğuştan geldiğine olan inançları azaldıkça akademik başarılarının artığı sonucuna ulaşmışır. $\mathrm{Bu}$ alanda öğrencilerle yapılan farklı çalışmalar incelendiğinde de öğrencilerin akademik başarıları ile epistemolojik inançlarının birbirleri ile ilişkili olduğunu ortaya koyan sonuçlar mevcuttur (Deryakulu ve Büyüköztürk, 2005; Kardash ve Scholes, 1996; Schommer, 1990; Schommer, Crouse, ve Rhodes, 1992, Schommer ve Walker, 1997; Topçu ve Yllmaz-Tüzün, 2009; Ünal-Çoban ve Ergin, 2008). Bu bağlamda düşünüldüğünde epistemolojik inançlar öğrencilerin akademik başarıları üzerinde etkili olan önemli değişkenlerden bir tanesi olduğu söylenebilir.

Fen eğitiminde ise kişisel epistemoloji ile ilgili olarak epistemolojik inançların doğasını, öğrenme ile ilişkisini ve sınıfta uygulanan öğretim yöntemlerinden nasıl etkilendiğini araştıran önemli çalışmalar yer almıştır (Bektaş, 2011; Gök, 2014; Hofer ve Pintrich, 1997; Sandoval, 2003; Tsai, 1998; Yerdelen-Damar, 2013). Öğrencilerin fene yönelik epistemolojik inançları, onların bir etkinlik ya da verilen bir göreve yönelik yaklaşımlarını, bilgilerini, çalışma yöntemlerini, argüman kalitelerini ve muhakeme yeteneklerini etkilemektedir (Hammer ve Elby, 2002; Hogan, 1999; Rosenberg, Hammer ve Phelan, 2006). Bu nedenle fen derslerinde öğrencilerin epistemolojik inançlarının belirlenerek öğrenme ve öğretme süreçlerinde dikkate alınmalıdır.

Farklı ülkelerde geliştirilen epistemolojik inanç ölçeklerinden bazılarının (Conley ve ark., 2004) Türkçe'ye çeviri ve uyumu yapıldığında ölçek boyutlarının sayısında ve boyutların isimlendirilmesinde değişiklikler olduğu görülmüsstür (Özkan, 2008). Benzer şekilde daha yükssek sınıf seviyeleri için hazırlanan ölçekler, küçük sınıflarda kullanıldığında da ölçeğin boyutlarında değişim olduğu görülmektedir (Schommer-Aikins, Mau, Brookhart ve Hutter, 2000). Dolayısiyla doğrudan ortaokul seviyesindeki öğrencilerin epistemolojik inançlarını belirlemeye yönelik hazırlanmış kapsamlı ölçeklerin geliştirilmesi bir ihtiyaçtır. Bu ihtiyaca yönelik olarak geliştirilen bir ölçekte (Üztemur, Dinç ve İnel, 2018), araştırmacılar hazırladıkları epistemolojik inanç ölçeğinin doğuştan yetenek, uzman otoritesi, hızlı öğrenme ve basit bilgi boyutlarını içerdiği sonucuna ulaşmışlardır. Bu ölçek dört boyutlu yapısı nedeniyle alanyazındaki yukarıda belirtilen boyutlardan kesin bilgi, gerekçelendirme ve günlük yaşama uyarlama boyutlarını içermemektedir. Buradan hareketle bu çalşsmada Schommer'in epistemolojik görüşleri dikkate alınmış ve çalışmada geliştirilecek ölçeğe rehberlik edecek felsefi düşünce Schommer'in epistemoloji üzerine temellendirdiği 
düşünceleri olmuştur. Dolayısıyla, bu çalışmada Schommer'in epistemolojik inanç modellerinde yer alan boyutları içeren ve doğrudan ortaokul seviyesindeki öğrencilerin epistemolojik inançlarını ölçmeye yönelik bir ölçek geliştirmek amaçlanmıştır. Bu amaç doğrultusunda yanıt aranan araştırma soruları şunlardır;

1. Hazırlanan epistemolojik inanç ölçeği geçerli midir?

2. Hazırlanan epistemolojik inanç ölçeği güvenilir midir?

\section{Yöntem}

Bu bölümde çalışmanın evren ve örneklemi, kullanılan veri toplama aracı ve verilerin analizine ilişkin bilgiler sunulmuştur. Her bir bölüm ilgili başlık altında açıklanmıştır.

\section{Evren - Örneklem}

Araştırmanın örneklemini Kayseri ili Kocasinan ilçesindeki farklı ortaokullarda okuyan 700 yedinci ve sekizinci sınıf öğrencisi oluşturmaktadır. Bu öğrencilerin 284'ü 7. Sınıf ve 416's1 ise 8. sinıfta öğrenim görmektedir. Ayrıca bu öğrencilerin 376'sı kız, 234’ü ise erkektir. Öğrencilerin yaşları 11 ile 15 aralı̆̆ında değişmektedir. Çalışma grubuna alınacak öğrenciler seçkisiz olmayan örnekleme yöntemlerinden uygun örnekleme yöntemine göre belirlenmiştir. Uygun örnekleme yönteminde araştırmacı en ulaşılabilir durumda olan katılımcılardan başlayarak çalışmasında zaman ve ekonomik açıdan en fazla tasarruf sağlayacak grup ile çalışır (Büyüköztürk vd., 2014).

\section{Veri Toplama Araçları}

Epistemolojik Inanc Ölçeği. Çalışmanın veri toplama aracı olan epistemolojik inanç ölçeği (EÏÖ) hazırlanırken öncelikle alanyazın taraması yapılmışır (Boz, Aydemir ve Aydemir. 2011; Conley, Pintrich, Vekiri ve Harrison 2004; Gök, 2014; Kızılgüneş, Tekkaya ve Sungur, 2009; Pamuk, 2014; Schraw, Bendixen ve Dunkle, 2002; Tucel, 2016). Yapılan alan yazın taraması sonucunda Conley, Pintrich, Vekiri ve Harrison (2004) tarafindan geliştirilip, çeviri ve adaptasyonu Özkan (2008) tarafından yapılan ölçekten, Schommer (1990) tarafindan geliştirilip, Deryakulu ve Büyüköztürk (2005) tarafından Türkçe 'ye uyarlanan ölçekten ve Schraw, Bendixen ve Dunkle (2002) tarafindan geliştirilen ölçekten faydalanılarak 64 maddeden oluşan ve her maddesi beşli likert tipinde yantlar içeren bir epistemolojik inanç ölçeği ön uygulama formu oluşturulmuştur. Bu formun içerdiği alt boyutlar basit bilgi, bilginin kaynağı, bilginin kesinliği, bilginin gelişimi, bilginin doğrulanması ve öğrenmenin hızı şeklindedir.

\section{Verilerin Analizi}

Araştırma verilerinin analizinde SPSS ve LISREL paket programları kullanılmıştır. Testin kapsam geçerliği için hazırlanan ön uygulama formu ölçek geliştirme ve epistemolojik inançlarla ilgili çalışmaları bulunan iki fen eğitim uzmanı tarafından incelenmiştir. Uzman görüşleri sonucunda ölçeğin her bir boyutundaki madde sayıları artırılmıştır. Testin yapı geçerliği için açımlayıcı ve doğrulayıcı faktör analizleri yürütülmüştür. Testin güvenilirliği için ise Cronbach Alfa güvenirlik katsayısı hesaplanmışır.

\section{Bulgular}

Hazırlanan taslak epistemolojik inanç ölçeği Kayseri ilindeki ortaokullarda öğrenim görmekte olan 700 ögrenciye uygulanmıştır. Uygulama sonuçları geçerlik ve güvenirlik çalısmaları yapılmak üzere SPSS 22 paket programına girilmiştir. Veri girişi esnasında 28 öğrencinin verilerinin eksik girildiği görülmüş ve bu öğrenciler çalışmadan çıkarılarak analizler 672 öğrencinin yanıtları üzerinden yürütülmüştür. Veri girişi tamamlandıktan sonra ölçekteki ters kodlu maddeler $(2,4,6,13,14,15,17,19,20,21,24,25,27,28,29$, $30,32,33,39,40,42,43,44,47,48,49,50,51,52,53,54,55,56,60,61$ ve 62 . Maddeler) yeniden kodlama işlemine tabi tutulmuştur.

Veri temizleme ve ölçekteki ters kodlu maddelerin yeniden kodlanmasından sonra yapı geçerliği kapsamında öncelikle açımlayıcı faktör analizine geçilmiştir. Yapılan ilk faktör analizinde ölçekteki 64 maddenin 18 faktör altında toplandığı görülmüştür. Daha sonra ölçekteki maddeler önce yedi sonra da altı ve beş faktöre sınırlandırılarak faktör analizi yürütülmüştür. Yürütülen analiz sonucunda KMO değeri .899 olarak bulunmuştur. Bu değerin faktör analizi için yeterli olduğu söylenebilir (Pallant, 2017). Ancak bu analiz sonucunda açılanan toplam varyansın düşük olmasından (\%33) ve her bir maddenin toplam varyansın açıklanmasındaki etkisini gösteren "Communalities" tablosunda bazı değerlerin .30'dan daha düşük olmasından dolay1 5, 13, 14, 16, 17, 18, 23, 26, 27, 39, 54, 58, 59, 63 ve 64. maddeler ölçekten çıkarılmıştır. Ayrıca ölçekte binişik madde olup olmadığı incelenmiştir. Binişik madde bir maddenin birden 
fazla faktör altında yeterli düzeyde faktör yüküne sahip olması durumudur. Bu durumda binişik maddeleri belirleyip ve ölçekten çıkarıp çıkarmamaya karar verirken, bir maddenin farklı faktörler altındaki faktör yük değerleri arasında en az .10 puanlık bir farklılık olmasına dikkat edilir (Seçer, 2017). Bu değerler incelenerek ölçekteki 32, 33 ve 44. maddeler binişik olduklarından dolayı ölçekten çıkarılmıştır. Daha sonra faktör analizi beş faktöre sınırlandırılarak tekrar yürütülmüştür. Belirlenen beş boyut altında toplanan maddeler için her boyutun güvenirlik analizi sonuçları kontrol edildiğinde boyutlardan birinin Cronbach's alpha güvenirlik katsayısı değerinin kabul edilebilir sınırın altında olduğu görülmüştür (.149) bulunmuştur. Güvenirlik katsayısı çok düşük olduğundan dolayı bu boyuttaki maddeler $(6,7,20,21,34,56,57$ ve 62 . maddeler) ve ölçeğin güvenirlik katsayısını düşürdügü görülen 1, 3, 4, 15, 19, 30, 41, 53. maddeler ölçekten çıkarılmıştır.

Ayrıca SPSS çıktılarında bulunan "Item Total Statistic" tablosundaki her bir maddenin toplam puanla ilişkisini belirleyen "Corrected Item-Total Correlation" değeri .3’ten küçük olan maddelerin ölçeğin toplamından farklı bir şey ölçtügünü gösterir (Pallant. 2017). Bu tablo incelenerek ölçekteki 38. ve 55. maddelerin değerleri .3’ten küçük olduğu için ölçekten çıkarılması kararlaştırılmıştır. Daha sonra kalan 29 madde üzerinden faktör analizi yürütülerek bulunan sonuçlar aşağıda rapor edilmiştir.

Tablo 1. KMO ve Barlett's Test Sonuclar

\begin{tabular}{lll}
\hline Kaiser-Meyer-Olkin Örneklem Yeterliliğ̈i & & $\mathbf{. 8 9 6}$ \\
\hline \multirow{2}{*}{ Bartlett Test Küreselliği } & Ki-Kare Değeri & 4969.829 \\
& S. Derecesi & 406 \\
& P & .000 \\
\hline
\end{tabular}

Kaiser- Meyer-Olkin (KMO) testi faktör analizi yapılırken araştırmanın örnekleminden toplanan verilerin yeterli olup olmadığının belirlenmesinde kullanılır. KMO örneklem yeterliliği değerinin bire (1) yaklaşması örneklem büyüklügünün yeterli olduğunun bir göstergesi iken bu değer 0.50 'nin altında ise örneklem büyüklüğünün yeterli olmadığını göstermektedir (Tavşancıl, 2005). Çalışmada elde edilen .896 KMO değeri dikkate alındığında çalışmada belirlenen örneklemin yeterli büyüklükte olduğu ve toplanan verilerin faktör analizi yürütmek için yeterli ve uygun olduğu söylenebilir. Bartlett değerlerinin istatistiksel olarak anlamlı çıkması da verilerin çok değişkenli normal dağılımı sağladığı varsayımını desteklemektedir.

KMO değeri kontrol edildikten sonra faktör analizine devam edilmiş ve ölçekte kalan 29 maddenin dört faktör altında toplandığı görülmüştür. Bu dört faktörün ise toplam varyansın \%42.86'sının açıklandığ1 Tablo 2'de görülmektedir.

Tablo 2. Açklanan Toplam Varyans

\begin{tabular}{llll}
\hline Faktör & Özdeğer & Varyansin Yüzdesi & Toplam Yüzde \\
\hline 1 & 6.05 & 20.866 & 20.86 \\
2 & 3.62 & 12.485 & 33.35 \\
3 & 1.45 & 5.021 & 38.37 \\
4 & 1.30 & 4.490 & 42.86 \\
\hline
\end{tabular}

Direct Oblimin dik döndürme tekniği kullanılarak maddelerin faktörlere dağılımına bakıldığında ölçeğin özdeğeri (eigen value) 1'den büyük dört faktörde toplandı̆̆1, tüm maddelerin girdikleri faktörde kabul edilebilir yük değerlerine sahip (en düşük madde yük değerinin .367; en yüksek madde yük değerinin .753) olduğu görülmüsstür (Tablo 3). Bu faktörlere ait scree plot grafiği Şekil 1'de verilmiştir. 
KIZKAPAN ve BEKTAŞ

Ortaokul Öğrencileri İçin Fene Yönelik Epistemolojik İnanç Ölçeği Geliştirilmesi: Geçerlik ve Güvenirlik Çalışması

Tablo 3. Pattern Matrix Tablosu

\begin{tabular}{|c|c|c|c|c|}
\hline & \multicolumn{4}{|c|}{ Faktörler } \\
\hline & 1 & 2 & 3 & 4 \\
\hline Madde60 & .728 & & & \\
\hline Madde50 & .708 & & & \\
\hline Madde51 & .641 & & & \\
\hline Madde48 & .615 & & & \\
\hline Madde 52 & .596 & & & \\
\hline Madde61 & .592 & & & \\
\hline Madde47 & .591 & & & \\
\hline Madde28 & .587 & & & \\
\hline Madde42 & .558 & & & \\
\hline Madde40 & .542 & & & \\
\hline Madde29 & .526 & & & \\
\hline Madde46 & & .753 & & \\
\hline Madde36 & & .675 & & \\
\hline Madde37 & & .656 & & \\
\hline Madde45 & & .655 & & \\
\hline Madde23 & & .619 & & \\
\hline Madde8 & & .572 & & \\
\hline Madde31 & & .535 & & \\
\hline Madde22 & & .494 & & \\
\hline Madde9 & & .367 & & \\
\hline Madde2 & & & .677 & \\
\hline Madde25 & & & .676 & \\
\hline Madde24 & & & .608 & \\
\hline Madde49 & & & .441 & \\
\hline Madde43 & & & .383 & \\
\hline Madde10 & & & & .773 \\
\hline Madde12 & & & & .674 \\
\hline Madde11 & & & & .492 \\
\hline Madde35 & & & & .447 \\
\hline
\end{tabular}




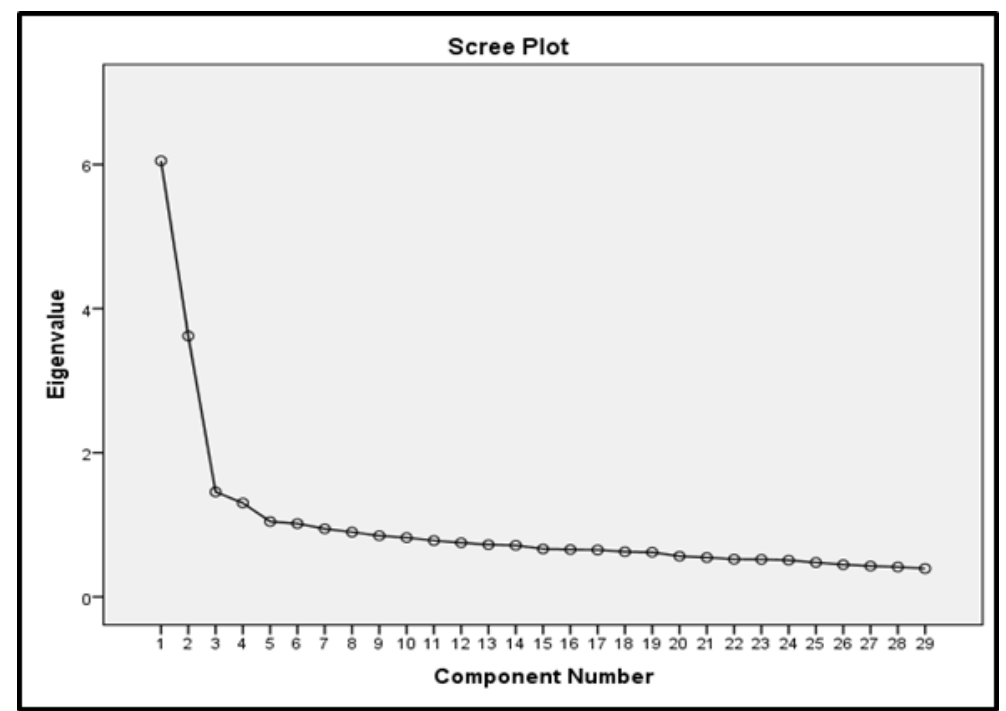

Şekil 1. Epistemolojik İnanç Ölçeğine Ait Scree Plot

Faktör analizi sonucu belirlen dört faktörü isimlendirmek için bir alan uzmanı ile çalışılmış ve ölçekteki birinci faktör "Kesin Bilgi”, ikinci faktör "Bilginin Kaynağı", üçüncü faktör "Öğrenme Yeteneği Doğuştandır" ve dördüncü faktör de "Bilginin Gelişimi" olarak isimlendirilmiştir. Ölçekteki kalan maddelerin ölçeğin nihai halindeki numaraları ve boyutlara dağılımları ve örnek maddeler Tablo 4'te verilmiștir.

Tablo 4. Epistemolojik İnanç Ölçeğinin Boyutlarv ve Boyutlarda Bulanan Maddeler

\begin{tabular}{lll}
\hline \multicolumn{1}{c}{ Ölçeğin Boyutları } & \multicolumn{1}{c}{ Maddeler } & \multicolumn{1}{c}{ Örnek Madde } \\
\hline Kesin Bilgi & $11,12,17,8,22,23,25,26,27,28,29$ & Bilimde, bütün soruların tek bir doğru cevabı vardır. \\
Bilginin Kaynağı & $2,3,7,8,13,15,16,20,21$ & $\begin{array}{l}\text { Bir şeyin doğru olup olmadığını anlamak için deney } \\
\text { yapmak iyi bir yoldur. }\end{array}$ \\
$\begin{array}{l}\text { Öğrenme Yeteneği } \\
\text { Doğuştandır }\end{array}$ & $1,9,10,19,24$ & $\begin{array}{l}\text { Okulda ne kadar başarılı olduğunuz ne kadar zeki } \\
\text { olduğunuza bağlıdır. }\end{array}$ \\
Bilginin Gelişimi & $4,5,6,14$ & Bilimsel kitaplardaki bilgiler bazen değişir. \\
\hline
\end{tabular}

Ölçeğin açımlayıcı faktör analizi ile belirlenen faktör yapısını doğrulamak için açımlayıcı faktör analizinden sonra LISREL programı kullanılarak doğrulayıcı faktör analizi (DFA) yapılmıştır. Doğrulayıc1 faktör analizlerinden önce verilerin normal dağılıp dağılmadığı kontrol edilmiştir. Toplanan verilerin normalliği basıklık ve çarpıklık değerleri kontrol edilerek yapılmıştır. Ölçekteki maddelere ait en yüksek basıklık değeri 1.542, en yüksek çarpıklık değeri ise -1.469 olarak hesaplanmıştır. Dolayısıyla basıklık ve çarpıklık değerleri $+2 /-2$ aralığını aşmadığından dolayı verilerin normal dağıldığı kabul edilmiştir (George ve Mallery, 2001). Normallik kontrolünden sonra doğrulayıcı faktör analizine geçilmiştir.

Yapılan doğrulayıcı faktör analizi sonucunda elde edilen path diyagramı (Şekil 2) ve uyum değerleri (Tablo 5) aşağıda rapor edilmiştir. Doğrulayıcı faktör analizinde Path Diagramında öncelikle t değerlerine bakılmalı, t değeri anlamlı çıkmayan maddeler ölçekten çıkarılmalıdır (Seçer, 2017). Şekil 2'deki gibi " $\mathrm{t}$ " değerleri açısından bir sorun bulunmaması durumunda ise öncelikle her bir maddenin faktör yük değerlerinin hesaplanması gerekmektedir. Faktör yük değerlerinin her bir madde için en az .30 ve üzeri yük değerine sahip olması gerekmektedir (Seçer, 2017). Bu çalışma için her bir maddenin faktör yük değerinin istenilen düzeyin üstünde olduğu görülmektedir (Şekil 2'de en soldaki değerler). "t" değerinin ardından çalışma için model uyum indekslerinin incelenmesine geçilmiştir. 


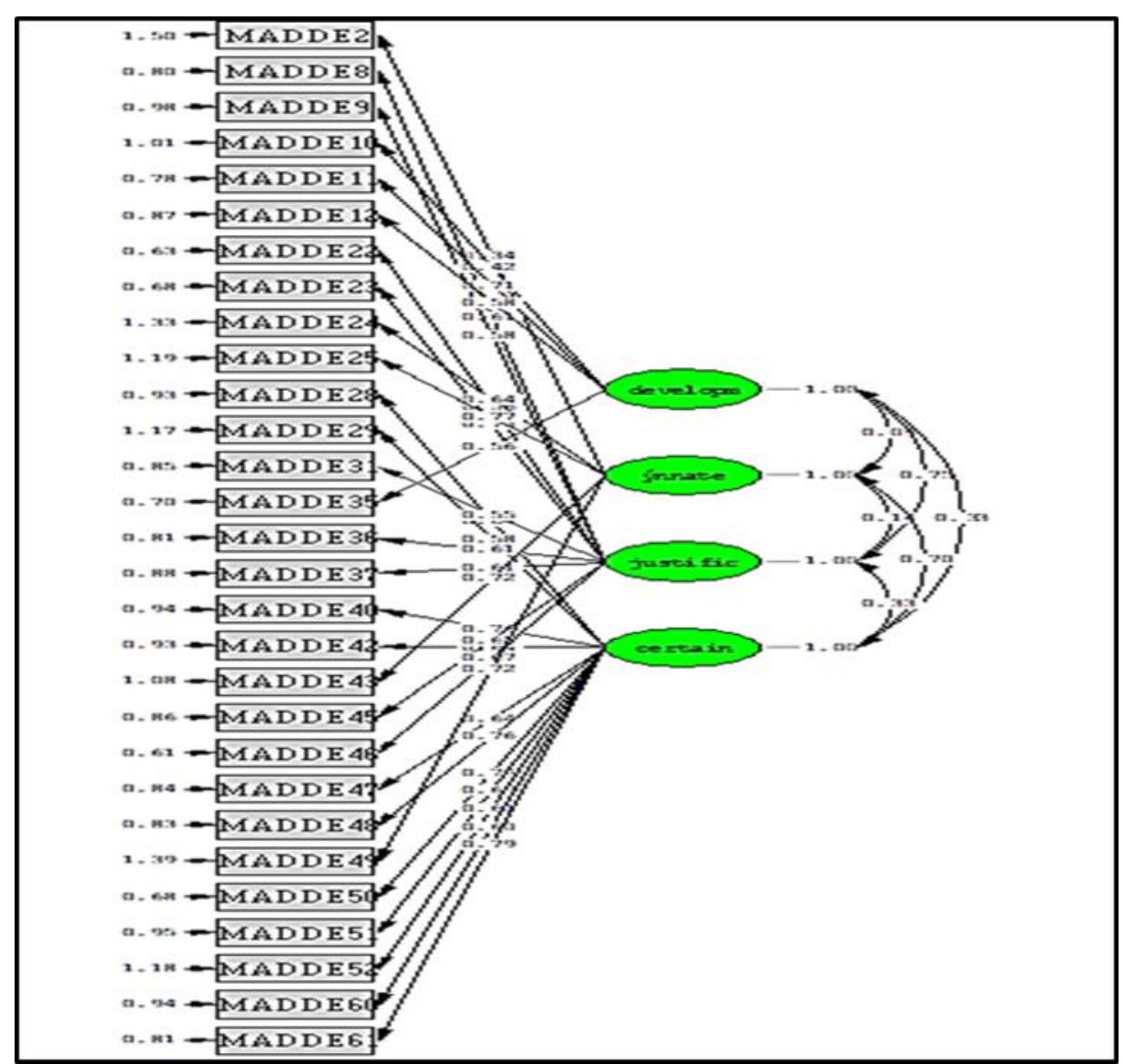

Şekil 2. EIÖ Doğrulaync Faktör Analiz̨ine Ait Path Dijagram

DFA' da uyumlu olup olmadığ sınanan modelin yeterliğini ortaya koymak üzere pek çok uyum indeksi kullanılmaktadır. Bu çalışmada yapılan DFA Ki kare uyum testi, GFI, RMSEA, CFI, NFI, RFI, IFI ve AGFI uyum indeksleri incelenmiştir. GFI, CFI, NFI, RFI, IFI ve AGFI indeksleri için kabul edilebilir uyum değeri .90 ve mükemmel uyum değeri .95 olarak kabul edilmektedir (Brown ve Cudeck, 1993; Meydan ve Şeşen, 2011). Belirtilen uyum indeksleri ve ölçeğe ait DFA sonuçları Tablo 5'te verilmiştir.

Tablo 5. DFA Uyum İndekslerine Ait Sinur Değerler ve Ölçekten Elde Edilen Sonuclar

\begin{tabular}{llll}
\hline \multicolumn{1}{c}{ Uyum Indeksi } & \multicolumn{1}{c}{ Kabul Edilebilir Sinır } & \multicolumn{1}{c}{ Mükemmel Uyum Sinırı } & Ölçeğe Ait Değer \\
\hline NFI & $=.90$ ve üzeri & $=.95$ ve üzeri & .93 \\
GFI & $=.85$ ve üzeri & $=.90$ ve üzeri & .91 \\
CFI & $=.95$ ve üzeri & $=.97$ ve üzeri & .96 \\
RFI & $=.90$ ve üzeri & $=.95$ ve üzeri & .92 \\
IFI & $=.90$ ve üzeri & $=.95$ ve üzeri & .96 \\
AGFI & $=.85$ ve üzeri & $=.90$ ve üzeri & .90 \\
REMSEA & $=.50$ ve $=.80$ arasi & $=.000$ ve $<.050$ arasi & .047 \\
$\mathrm{X}^{2} / \mathrm{sd}$ & Bulanan değer istatistiksel olarak anlamsiz olmalıdır ve $\mathrm{X}^{2} / \mathrm{sd}<3$ olmalıdır. & 2.41 \\
\hline
\end{tabular}

Ölçeğin dört boyutlu yapıda olduğu bulunmuş ve bulunan bu boyutlar doğrulayıcı faktör analizi ile teyit edilmiştir. Faktör analizine çıkarılan maddelerden sonra ölçeğin güvenirliği kapsamında güvenirlik analizi yürütülmüştür. Bu analizde Cronbach's Alfa güvenirlik katsayısına ilişkin bulunan sonuçlar Tablo 6'da verilmiştir. 
Tablo 6. Güvenirlik Analiæi Sonuçar

\begin{tabular}{llll}
\hline & Boyutlar & Madde Say1S1 & Cronbach Alfa \\
\hline Kesin Bilgi & 11 & .846 & \\
Bilginin Kaynă̆ı & 9 & .812 \\
Öğrenme Yeteneği Doğuştandır & 5 & .610 \\
Bilginin Gelişimi & 4 & .616 \\
Tüm ölçek & 29 & .747 \\
\hline
\end{tabular}

Tablo 6'da görüldüğü gibi ölçeğin Cronbach Alfa güvenirlik katsayısı hem her bir ölçek alt boyutu hem de ölçeğin tamamı için hesaplanmıştır. Ölçeğin Cronbach Alfa güvenirlik katsayısı "kesin bilgi" alt boyutu için .846, "bilginin kaynağı" alt boyutu için .812, "öğrenme yeteneği doğuştandır" alt boyutu için .610 ve bilginin gelişimi alt boyutu için .616 olarak bulunmuştur.

\section{Tartışma, Sonuç ve Öneriler}

Öğrencilerin kavramsal öğrenmelerini etkileyen değişkenlerden birisinin sahip oldukları epistemolojik inançlar olduğu söylenebilir. Öğrenme üzerinde önemli belirleyici etkileri olan epistemolojik inançların öğrencilerin ders çalışma alışkanlıkları (Schommer, Crouse ve Rhodes, 1992), akademik başarıları (Schommer, 1993), tutumlar1 (Schommer ve Walker, 1997) ve düşünme becerileri (Schommer-Aikins ve Hutter, 2002) gibi birçok faktör üzerinde etkileri olduğu çalışmalarda rapor edilmiştir (Deryakulu ve Büyüköztürk, 2005). Dolayısıyla öğrencilerin sahip oldukları epistemolojik inançların doğru bir şekilde belirlenebilmesi önemlidir.

Alanyazındaki epistemolojik inanç ölçekleri incelendiğinde yabancı dilde hazırlanan bir ölçeğin Türkçe’ye uyarlandığında (Yılmaz-Tüzün ve Topçu, 2010) veya bir eğitim düzeyine yönelik hazırlanmış bir ölçeğin başka seviyelerdeki öğrencilerin epistemolojik inançlarını belirlemek için kullanıldı̆̆ında (Schommer-Aikins, Brookhart ve Hutter; 2000) ölçekteki madde ve boyut sayılarında değişiklikler ortaya çıkabilmektedir. $\mathrm{Bu}$ gerekçelerden hareketle gerçekleştirilen bu çalışmada ortaokul seviyesindeki öğrencilerin fene yönelik epistemolojik inançlarını belirlemekte kullanılabilecek bir ölçek geliştirmek amaçlanmıştır. Bu ölçek planlanırken ölçeğin literatürde yer alan farklı epistemolojik inanç modellerinin boyutlarını içeren kapsamlı bir ölçek olmasına dikkat edilmiştir. Ancak bu gerekçelerle başlangıçta yedi boyutlu olarak planlanan ölçeğin boyut sayısı yapılan analizler sonucunda dörde inmiştir. Bu boyutlar kuramsal yapıya uygun olarak "kesin bilgi", "bilginin kaynağı", "bilginin gelişimi" ve "öğrenme yeteneği doğuştandır" şeklinde isimlendirilmiştir. Çalışmanın başlangıcında üç farklı epistemolojik inanç modelinden yedi farklı boyuta ilişkin maddeler ölçeğe dâhil edilmiş olsa da nihai olarak ölçekte sadece Schommer'ın (1990) modelinde bulunan boyutlar kalmıştır. Bu sonuç farklı modellere ait boyutların bir ölçekte bir araya gelmediğini göstermiştir.

Epistemolojik inanç ölçeği geliştirme amacıyla gerçekleştirilen bu çalışmada öncelikle alanyazın taramas1 yapılmıştır (Boz, Aydemir ve Aydemir. 2011; Conley, Pintrich, Vekiri ve Harrison 2004; Gök, 2014; Kızıllgüneş, Tekkaya ve Sungur, 2009; Pamuk, 2014; Schraw, Bendixen ve Dunkle, 2002; Tucel, 2016). Alanyazın taraması sonucunda oluşturulan 64 maddelik ölçek kapsam geçerliğinin kontrolü için uzman görüşüne sunulmuştur. Daha sonra 700 öğrenciye uygulanan ölçekten toplanan verilerle ölçeğin yap1 geçerliğini kontrol etmek için açımlayıcı faktör analizi (AFA) yapılmıştır. Yapılan AFA sonucunda ölçek maddelerinin dört boyut altında toplandığı ve toplam varyansın \%42.86'sının açıklandığ1 görülmüştür. Ölçek geliştirme çalışmalarında açıklanan varyans oranı ile ilgili alanyazında farklı sınır değerlerin benimsendiği görülmektedir. Henson ve Robets (2006)'e göre bu oranın en az \%52 olmas1 gerekirken, Kline (2011) ölçekteki maddelerin toplam varyansin en az \%40'inı açıklaması gerektiğini belirtmiştir. Dolayısıyla Kline (2011)'in sonucundan hareketle çalışmada elde edilen değerin ölçeğin faktör yapısına karar vermek için yeterli olduğu kabul edilmiştir. Yapılan AFA'dan sonra ortaya çıkan faktör yapısını doğrulamak için doğrulayıcı faktör analizi (DFA) yapılmıştır. Yapılan DFA sonucunda model uyum indekslerinin $\left(\mathrm{X}^{2} / \mathrm{sd}=2.41, \mathrm{NFI}=.93\right.$, GFI $=.91, \mathrm{CFI}=.96, \mathrm{RFI}=.92, \mathrm{IFI}=.96, \mathrm{AGFI}=.90$ ve REMSEA=.047) kabul edilebilir sınırlarda olduğu görülmüştür (Marcoulides ve Schumacher, 2001; Schumacher ve Lomax, 2004; Kline, 2005).

Ortaokul öğrencilerine yönelik epistemolojik inanç ölçeğinin faktör yapısını belirledikten sonra güvenirliğini belirlemeye yönelik analizler gerçekleştirilmiştir. Ölçeğin Cronbach Alfa güvenirlik katsayıs1 
"kesin bilgi" alt boyutu için .846, "bilginin kaynağı" alt boyutu için .812, "öğrenme yeteneği doğuştandır" alt boyutu için .610 ve bilginin gelişimi alt boyutu için .616 olarak bulunmuştur. Tüm ölçeğin Cronbach Alfa iç tutarlık sonucu ise .744 olarak bulunmuştur. Sıfır (0) ile bir (1) arasında değerler alabilen güvenirlik katsayısı değeri bire yaklaştıkça ölçeğin güvenirliği artar (Gömleksiz ve Erkan, 2010). Yapılan analiz sonucunda "Öğrenme yeteneği doğuştandır" ve "bilginin gelişimi” alt boyutlarında güvenirlik değerleri madde sayısının az olmasına bağlı olarak nispeten düşük olsa da elde edilen Cronbach alfa değerleri kabul edilebilir aralıkta bulunduğu söylenebilir (Griethuijsen vd., 2015; Taber, 2018).

$\mathrm{Bu}$ çalışmada epistemolojik inanç ölçeğinin analizleri Kayseri ili, Kocasinan ilçesindeki benzer niteliklere sahip öğrencilerden toplanan verilere dayalı olarak gerçekleştirilmiştir. Bu durumun çalışmanın sinırlılıkları arasında olduğu söylenebilir. Dolayısıyla farklı coğrafi bölgelerden ve farklı sosyoekonomik düzeylerden öğrencilerden toplanacak verilerle tekrar edilmesi önerilebilir.

\section{Etik Beyan}

"Epistemolojik Inanc Ölçeği Geliştirilmesi. Geçerlik ve Güvenirlik Çalısması" başlıklı çalışmanın yazım sürecinde bilimsel, etik ve alıntı kurallarına uyulmuş; toplanan veriler üzerinde herhangi bir tahrifat yapılmamış ve bu çalışma herhangi başka bir akademik yayın ortamına değerlendirme için gönderilmemiştir. Çalışma Nevşehir Hacı Bektaş Veli Üniversitesi etik kurulunun 12.03.2020 tarihli 08 sayılı toplantısında görüşülmüş ve çalışmanın gerçekleştirilmesinde etik sakınca bulunmadı̆̆ına karar verilmiştir.

\section{Kaynakça}

Baxter Magolda, M. B. (2004). of a constructivist conceptualization of epistemological reflection. Educational Psychologist, 39(1), 31-42.

Bektas. O. (2011). The effect of 5E learning gycle model on tenth grade students' understanding in the particulate nature of matter. epistemological beliefs and views of nature of science (Doctoral Dissertation). Middle East Technical University. Ankara, Turkey.

Boz. Y., Aydemir. M., ve Aydemir. N. (2011). 4th. 6th. and 8th grade Turkish elementary students` epistemological beliefs. Elementary Education Online, 10(3), 1191-1201.

Brown, M., ve Cudeck, R. (1993). EQS structural equations program manual. Los Angeles: Multivariate Software Inc.

Büyüköztürk, Ş., Çakmak, E., Akgün, Ö., Karadeniz, Ş. ve Demirel, F. (2014). Bilimsel araşttrma yöntemleri (17. Baskı). Ankara: Pegem Yayıncilık.

Chandler,M. J., Hallett, D., ve Sokol, B.W. (2002). Competing claims about competing knowledge claims. In B. K. Hofer ve P. R. Pintrich (Eds.), Personal epistemology: The psychology of beliefs about knowledge and knowing (pp. 145168). Mahwah, NJ: Erlbaum.

Conley. A. M. Pintrich. P. R.. Vekiri. I.. ve Harrison. D. (2004). Changes in epistemological beliefs in elementary science students. Contemporary Educational Psychology, 29, 186-204.

Deryakulu. D. ve Büyüköztürk. Ş. (2005). Epistemolojik inanç ölçeğinin faktör yapısının yeniden incelenmesi: Cinsiyet ve öğrenim görülen program türüne göre epistemolojik inançların karşılaştırılması. Eğitim Araştırmaları. 18, 57-70.

Elder, A. D. (2002). Characterizing fifth grade students' epistemological beliefs in science. In B. Hofer and P. R. Pintrich (Eds.). Personal Epistemology: The Psychology of Beliefs About Knowledge and Knowing (pp. 347-364). New Jersey: Lawrence Erlbaum.

Evcim, İ. (2010). İlkögretim 8. simı öğrencilerinin epistemolojik inanıslaryla, fen kazanımlarm günlük yaşamlarnda kullanabilme düzeyleri ve akademik başarlar arasındaki ilişkei (Yüksek Lisans Tezi). Marmara Üniversitesi Eğitim Bilimleri Enstitüsü, İstanbul.

George, D. ve Mallery, P. (2001). SPSS for Windows. Step by step (3 ${ }^{\text {rd }}$ Edition). USA: Allyn and Bacon.

Gök. G (2014). The effect of 7 le learning cycle instruction on 6th grade students' conceptual understanding of human body systems. selfregulation. scientific epistemological beliefs. and science process skills (Master Thesis). Gazi University, Ankara.

Gömleksiz, M. ve Erkan, S. (2010). Eğitimde ölcme ve değerlendirme (2. Baskı). Ankara: Nobel Yayın Dağıtım.

Griethuijsen, R. A., van Eijck, M. W., Haste, H., den Brok, P. J., Skinner, N. C., Mansour, N., ... ve BouJaoude, S. (2015). Global patterns in students' views of science and interest in science. Research in Science Education, 45(4), 581-603.

Hammer, D. ve Elby, A. (2002). On the form of a personal epistemology. Personal Epistemology: The Psychology of bEliefs About Knowledge And Knowing, 169-190.

Henson, R. K. ve Roberts, J. K. (2006). Use of exploratory factor analysis in published research: Common errors and some comment on improved practice. Educational and Psychological measurement, 66(3), 393-416.

Hofer. B. K.. ve Pintrich. P. R. (1997). The development of epistemological theories: Beliefs about knowledge and knowing and their relation to learning. Review of Educational Research, 67, 88-140.

Hofer, B. K. ve Pintrich, P. R. (2012). Personal epistemology: The psychology of beliefs about knowledge and knowing. Routledge. Hogan. K. (1999). Relating students' personal frameworks for science learning to their cognition in collaborative contexts. Science Education. 83(1). 1-32. 
Kardash. C. M. ve Scholes. R. J. (1996). Effects of pre-existing beliefs. epistemological beliefs. and need for cognition oninterpretation of controversial issues. Journal of Educational Psychology. 88. 260-271.

Kızılgünes. B.. Tekkaya. C. ve Sungur. S. (2009). Modeling the relations among students' epistemological beliefs, motivation, learning approach and achievement. The Journal of Educational Research.102(4). 243-255.

King, P. M. ve Kitchener, K. S. (1994). Developing reflective judgment: Understanding and promoting intellectual growth and critical thinking in adolescents and adults. San Francisco: Jossey-Bass.

King, P. M. ve Kitchener, K. S. (2004). Reflective judgment: Theory and research on the development of epistemic assumptions through adulthood. Educational Psychologist, 39, 5-18.

Kline, R. B (2011). An easy guide to factor analysis. New York: The Guilford Press

Kuhn, D., Cheney, R. ve Weinstock, M. (2000). The development of epistemological understanding. Cognitive Development, 15, 309-328.

Marcoulides, G., and Schumacher, R. (2001). New developments and techniques in structural Equation modeling. London: Lawrence Erlbaum Associates, Publishers.

Meydan, C. H., ve Şeşen, H. (2011). Yapısal eşitlik modellemesi AMOS uygulamalar. Detay Yayınc1l1k.

Özkan. S.. (2008). Modeling elementary students' science achievement: the interrelationships among epistemological beliefs. learning approaches. and self-regulated learning strategies (Doctoral Thesis). Middle East Technical University. Ankara.

Pallant, J. (2017). Spss kullanma kilavuzu - Spss ile adım adım veri analizi (Çev: S. Balc1 ve B. Ahi) Ankara: Anı Yayıncılık.

Pamuk. S. (2014). Multilevel analysis of students science achievement in relation to constructivist learning environment perceptions. epistemological beliefs. self-regulation and science teachers characteristics (Master Thesis). Gazi University. Ankara.

Perry, W. G. (1970). Forms of intellectual and ethical development in the college years: A scheme. New York: Holt, Rinehart and Winston.

Perry W. G. (1981). Cognitive and ethical growth: The making of meaning. In. A. Chickering (Ed.). The modern American college. (pp. 76-116). San Francisco:Jossey-Bass.

Pintrich, P. R. (2002). Future challenges and directions for theory and research on personal epistemology.In P. R. Pintrich (Ed.), Personal epistemology: The psychology of beliefs about knowledge and knowing Mahwah, NJ, USA: Lawrence Erlbaum Associates

Rosenberg. S. A.. Hammer. D. ve Phelan. J. (2006). Multiple epistemological coherences in an eighth-grade discussion of the rock cycle. Journal of the Learning Sciences, 15(2), 261-292.

Sandoval. W. A. (2003). Conceptual and epistemic aspects of students' scientific explanations. The Journal of the Learning Sciences, 12, 5-51.

Schommer-Aikins, M. ve Hutter, R. (2002). Epistemological beliefs and thinking about everyday controversial issues. The journal of Psychology, 136(1), 5-20.

Schommer-Aikins, M., Mau, W. C., Brookhart, S. ve Hutter, R. (2000). Understanding middle students' beliefs about knowledge and learning using a multidimensional paradigm. The Journal of Educational Research, 94(2), 120-127.

Schommer. M. (1990). Effects of beliefs about the nature of knowledge on comprehension. Journal of Educational Psychology, 82(3), 498-504.

Schommer. M. (1993). Epistemological development and academic performance among secondary students. Journal of Educational Psychology, 85, 406-411.

Schommer. M.. Crouse. A. ve Rhodes. N. (1992). Epistemological beliefs and mathematical text comprehension: Believing it is simple does not make it so. Journal of Educational Psychology, 84, 435-443.

Schommer. M.. ve Walker. K. (1997). Epistemological beliefs and valuing school: Considerations for college admissions andretention. Research in Higher Education. 38. 173-186.

Schraw. G.. Bendixen. L. D.. ve Dunkle. M. E. (2002). Development and validation of the Epistemic Belief Inventory (EBI). In B. K. Hofer ve P. R. Pintrich (Eds.). Personal epistemology: The psychology of beliefs about knowledge and knowing (pp. 261-275). Mahwah. NJ: Lawrence Erlbaum Associates.

Schumacker, R. E. ve Lomax, R. G., (2004). A beginner's guide to structural equation modeling. London: Lawrence Erlbaum Associates, Publishers.

Seçer, İ. (2017). Psikolojik test gelistirme ve uyarlama süreci: SPSS ve LISREL uygulamalar. Anı yayıncilık.

Taber, K. S. (2018). The use of Cronbach's alpha when developing and reporting research instruments in science education. Research in Science Education, 48(6), 1273-1296.

Tavşancıl, E. (2005). Tutumlarn ölçülmesi ve SPSS ile veri analið̧. Ankara: Nobel Yayın Dağıtım.

Topçu. M. S. ve Yılmaz-Tüzün. Ö. (2009). Elementary students' metacognition and epistemological beliefs considering science achievement. gender and socioeconomic status. Elementary Education Online, 8(3), 676-693.

Tsai. C. C. (1998). An analysis of scientific epistemological beliefs and learning orientations of Taiwanese eighth graders. Science Education, 82, 473-489.

Tucel. S. T. (2016). Exploring the effects of science writing heuristic (swh) approach on the eight grade students' achievement. metacognition and epistemological beliefs (Master Thesis). Gazi University. Ankara.

Ünal Çoban. G. ve Ergin. Ö. (2008). İlköğretim öğrencilerinin bilimsel bilgiye yönelik görüşlerini belirleme ölçeği. Illeögretim Online, 7(3), 706-716.

Üztemur, S., Dinç, E., ve İnel, Y. Ortaokul Öğrencilerinin Epistemolojik İnançlarının Ölçülmesi: Bir Ölçek Geliştirme Çalışması. Yü̊üncü Yal Üniversitesi Eğitim Fakültesi Dergisi, 15(1), 1459-1489. 
White, B.Y., Elby, A., Fredriksen, J.R. and Schwarz, C. (1999). The epistemological beliefs assessment for physical students. Presented at the American Educational Research Association (AERA), Montreal, Canada. http://www2.physics.umd.edu/ elby/EBAPS/home.html adresinden 02.20.2017 tarihinde erişilmiştir.

Yerdelen Damar. S. (2013). The effect of the instruction based on the epistemologically and metacognitvely improved $7 e$ learning cycle on tenth grade students' achrevement and epistemological understandings in physics (Doctoral Dissertation). Middle East Technical University, Ankara.

Yıldıran, D., Demirci, N., Tüysüz, M., Bektas, O. ve Geban, Ö. (2011). Adaptation of an epistemological belief instrument towards chemistry and chemistry lessons. Procedia-Social and Behavioral Sciences, 15, 3718-3722.

Yilmaz-Tüzün, Ö. ve Topcu, M. S. (2010). Investigating the relationships among elementary school students' epistemological beliefs, metacognition, and constructivist science learning environment. Journal of Science Teacher Education, 21(2), 255-273.

\section{EXTENDED ABSTRACT}

Students' epistemological beliefs in science affect their approaches, knowledge, working methods, argument quality and reasoning abilities towards an activity or a given task (Hammer, \& Elby, 2002; Hogan, 1999; Rosenberg, Hammer and Phelan, 2006). For this reason, the epistemological beliefs of the students should be determined and taken into consideration in the learning and teaching processes. When the scales developed in order to determine the epistemological beliefs of the students at different levels are examined, it is seen that the scales with different number and different named dimensions have been developed or adapted to Turkish. Although there is no consensus on the number and names of epistemological belief dimensions, it can be said that multidimensional models are superior to onedimensional models because they take into account the domain-specific nature of epistemological beliefs. Although there are scales developed or translated from different languages in order to determine epistemological beliefs in the literature, it is a need to develop comprehensive scales that are prepared to directly determine the epistemological beliefs of students at elementary level. In this study, unlike other studies, it is aimed to develop a scale that includes all epistemological belief dimensions in the literature and directly measures the epistemological beliefs of students at elementary level.

The sample of the study consists of 700 seventh and eighth grade students attending different elementary schools in Kocasinan district of Kayseri. Among these students, 284 of them are in 7 th grade and 416 of them are in 8th grade. In addition, 376 of these students are girls and 234 of them are boys. The sample of the study was determined by non-random sampling methods according to the appropriate sampling method.

While preparing the epistemological belief scale the literature was firstly searched. As a result of the literature review, an epistemological belief scale pre-application form consisting of 64 items with five Likert type responses was created. The sub-dimensions included in the pre-application form are simple knowledge, source of knowledge, certainty, development, of knowledge justification and speed of learning.

The pre-application form for the content validity of the test was examined by two science education experts who had studies on scale development and epistemological beliefs. Exploratory and confirmatory factor analyzes were conducted for the construct validity of the test. For the reliability of the test, Cronbach's alpha reliability coefficient was calculated.

As a result of exploratory factor analysis, a four factor structure was determined. In order to name these factors, an expert and the researchers examined the items of the factors and the first factor in the scale was named as certain knowledge, the second factor was source of knowledge, the third factor was innate ability and the fourth factor was named as development of knowledge. After exploratory factor analysis, confirmatory factor analysis was conducted. In the context of confirmatory factor analysis, the four-factor structure of the scale was confirmed as a result of the value obtained for GFI, CFI, NFI, RFI, IFI and AGFI indices.

Cronbach Alpha reliability coefficient of the scale was found to be .846 for the "certain knowledge" sub-dimension, .812 for the "source of knowledge" sub-dimension, .610 for the "innate ability" subdimension, and .616 for the "development of the knowledge" sub-dimension (Griethuijsen et al., 2015; Taber, 2018).

In this study, which was conducted with the aim of developing an epistemological belief scale, the literature was firstly searched (Boz, Aydemir, \& Aydemir. 2011; Conley, Pintrich, Vekiri, \& Harrison 2004; Gök, 2014; Kızılgüneş, Tekkaya, \& Sungur, 2009; Pamuk, 2014; Schraw, Bendixen, \& Dunkle, 2002; Tucel, 2016). As a result of the literature review, the 64-item scale was presented to the expert's opinion to 
check the content validity. Afterwards, exploratory factor analysis (EFA) was performed to check the construct validity of the scale with the data collected from the scale applied to 700 students. As a result of the EFA, it was seen that the scale items were gathered under four dimensions and $42.86 \%$ of the total variance was explained. It is seen that different limit values are adopted in the literature about the variance ratio explained in the scale development studies. According to Henson and Robets (2006), this ratio should be at least $52 \%$, while Kline (2011) stated that items in the scale should explain at least $40 \%$ of the total variance. Therefore, based on the result of Kline (2011), it was accepted that the value obtained in the study was sufficient to decide the factor structure of the scale. Confirmatory factor analysis (CFA) was performed to confirm the factor structure after the EFA. As a result of the DFA, model fit indexes $\left(\mathrm{X}^{2} / \mathrm{sd}\right.$ $=2.41, \mathrm{NFI}=.93, \mathrm{GFI}=.91 \mathrm{CFI}=.96, \mathrm{RFI}=.92 \mathrm{IFI}=.96, \mathrm{AGFI}=.90$ and REMSEA $=.047)$ are acceptable (Marcoulides, \& Schumacher, 2001; Schumacher, \& Lomax, 2004; Kline, 2005).

After determining the factor structure of the epistemological belief scale for elementary school students, analyzes were conducted to determine its reliability. Cronbach Alpha reliability coefficient of the scale was found to be .846 for the "certain knowledge" sub-dimension, .812 for the "source of knowledge" sub-dimension, .610 for the "innate ability" sub-dimension, and .616 for the "development of the knowledge" sub-dimension (Griethuijsen et al., 2015; Taber, 2018). Cronbach's alpha internal consistency coefficient was calculated as .744 for the whole scale. Therefore, it can be said that the scale has internal consistency reliability (Griethuijsen et al., 2015; Taber, 2018).

The epistemological belief scale prepared in the study can be used to measure the epistemological beliefs of elementary school students. However, in this study, the analysis of the epistemological belief scale was conducted based on the data collected from students with similar qualifications in Kocasinan district of Kayseri. This can be said to be among the limitations of the study. Therefore, it may be suggested to repeat the data to be collected from students from different geographical regions and different socioeconomic levels. 